\title{
LA JUSTICIA ÉTNICA COMO CRITERIO DE REPARACIÓN DE LAS VÍCTIMAS DEL DESPLAZAMIENTO FORZADO EN EL MARCO DEL CONFLICTO ARMADO EN COLOMBIA
}

\author{
ETHNIC JUTCICE AS A CRITERION FOR THE VICTIMS OF FORCED \\ DISPLACEMENT REPARATION IN THE CONTEXT OF THE ARMED \\ CONFLIC IN COLOMBIA
}

\section{JUSTIÇA ÉTNICA COMO CRITÉRIO PARA A REPARAÇÃO DE VÍTIMAS DE DESLOCAMENTO FORÇADO NO ÂMBITO DO CONFLITO ARMADO NA COLÔMBIA}

\author{
Keidy Jhoena Lemos Mena* \\ Yirsew Palacios Mosquera** \\ Gilbert Stein Vergara Mosquera***
}

\begin{abstract}
Resumen: El despojo masivo de tierras en Colombia presenta innumerables retos para la justicia transicional a partir de evidentes complejidades para la implementación de las políticas de restitución, que van desde la inexistencia de información catastral sistemática hasta la falta de títulos de propiedad por parte de campesinos poseedores que fueron desplazados de sus parcelas, pasando por homicidios de líderes y amenaza contra la vida de quienes reclaman la restitución. Por ello a través de la presente labor académicocientífica nos complacemos en presentar un interesante razonamiento que sin duda permitirá brindar las bases necesarias para diseñar políticas agrarias incluyentes y equitativas, que consientan construir y estructurar propuestas de políticas públicas, planes programas y proyectos encaminados a la reparación integral de víctimas afrodescendientes de desplazamiento forzado y otras graves violaciones de derechos humanos a partir de un enfoque étnico, para ser incorporados como referente de reparaciones colectivas a ese golpeado sector de la sociedad Colombiana, que con sustento en una realidad histórica, en normas internacionales y en la jurisprudencia nacional, demanda que dentro de los principios de justicia y enfoque diferencial, su problemática sea analizada y sus soluciones aplicadas desde una mirada especial. Se trata de la incorporación de un criterio de justicia que, a pesar de tener profundas repercusiones sociales, económicas y jurídicas en Colombia, no ha sido incluido sistemáticamente a la discusión y trazo de las políticas sobre reparaciones a las víctimas, esto es, un criterio de justicia étnica.
\end{abstract}

Palabras Clave: Conflicto armado; Desplazamiento Forzado; Enfoque Diferencial; Justicia Étnica; Mecanismos de protección y Reparación.

Abstract: The massive dispossession of land in Colombia induces innumerable challenges for transitional justice based on evident complexities for the implementation

\footnotetext{
* Universidad Tecnológica del Chocó "Diego Luis Córdoba. E-mail: jhokelemos@gmail.com.

** Universidad Tecnológica del Chocó "Diego Luis Córdoba. E-mail: yirsewpalacios@ hotmail.com.

**** Universidad Tecnológica del Chocó "Diego Luis Córdoba. E-mail: samuelitoiii09@gmail.com.
} 
of land restitution policies, ranging from the lack of systematic cadastral information to the lack of ownership titles of the peasants; who were displaced from their parcels, suffering homicides of leaders and threats against the lives of those who claim restitution. For this reason, through the present academic-scientific work, we are pleased to present an interesting reasoning that will undoubtedly provide the necessary basis for the design of inclusive and equitable agricultural policies, which will allow the construction and structuring of public policy proposals, plans and projects aimed at the integral reparation of afro-descendant victims of forced displacement and other serious violations of human rights based on an ethnic approach, to be incorporated as a reference for collective reparations to this oppressed region of the Colombian society, based on a historical reality, International rules and national jurisprudence; it is requesting that within the principles of justice and differential approach, its problematic must be analyzed and its solutions applied in every way. It is a matter of incorporating justice criteria that, despite having profound social, economic and legal repercussions in Colombia, has not been systematically included in the discussion and planning of the policies on reparations to victims, that is, ethnic justice criteria.

KEYWORDS: Armed Conflict; Compensation and Forced Displacement; Differential Approach; Ethnic Justice; Protection Mechanisms.

Resumo: A deposição maciça de terra na Colômbia apresenta inúmeros desafios para a justiça de transição com base em complexidades óbvias para a implementação de políticas de restituição, desde a falta de informação cadastral sistemática até a falta de títulos de propriedade por camponeses que possuem foram deslocados de suas parcelas, incluindo homicídios de líderes e ameaças contra a vida de quem reivindica a restituição. Por isso, através do presente apresentaremos um interessante raciocínio que, sem dúvida, fornecerá as bases necessárias para a concepção de políticas agrárias inclusivas e equitativas, que consubstanciam a construção e estruturação de propostas de políticas, planos, programas e projetos públicos voltados para a integração integral de vítimas de deslocamento forçado e outros violações graves dos direitos humanos com base em uma abordagem étnica a ser incorporada como referência para reparações coletivas a esse setor da sociedade colombiana, que, com base em uma realidade histórica, normas internacionais e jurisprudência nacional, exige que, dentro de dois princípios de justiça e abordagem diferencial, sua problemática seja analisada e suas soluções sejam aplicadas a partir de um aspecto especial. A incorporação de um critério de justiça que, apesar de suas profundas repercussões sociais, econômicas e legais na Colômbia, não é sistematicamente incluída na discussão das políticas de reparação às vítimas, ou seja, um critério de justiça étnica.

Palavras-chave: Conflitos armados; foco diferencial; Justiça étnica; Mecanismos de proteção; reparação forçada e deslocalização.

\section{INTRODUCCIÓN}

De acuerdo con nuestro trabajo investigativo ${ }^{1}$ desarrollado en el seno del semillero de investigación de Derecho procesal en la línea de Derecho Penal, la legislación interna, en los términos de la Ley 387 de 1997, 975 de 2005, la 1448 de 2011 
La justicia étnica como criterio de reparación de las víctimas del desplazamiento forzado en el marco del conflicto armado en Colombia

y sus Decretos Reglamentarios, el Derecho Internacional Humanitario y el derecho Internacional de los Derechos humanos, las víctimas tienen derecho a la verdad, a la justicia, a la reparación y a las garantías de no repetición. Estos derechos se hacen efectivos cuando se les brinda la posibilidad de participar durante el proceso para que aporten pruebas, denuncien bienes de los grupos armados organizados al margen de la ley o de sus miembros, brinden y reciban información, formulen su pretensión de reparación integral, entre otras modalidades de intervención.

Al respecto vale hacer una precisión, puesto que existen diferencias entre la reparación como derecho, y reparación como mecanismo de justicia transicional que es también un principio procesal de reparación de víctimas. En el primer caso, la naturaleza de la reparación de tipo jurídico generalmente está asociada a fallos judiciales y tiene como objetivo la compensación por el daño que ha sufrido una persona como consecuencia de un crimen específico. La reparación judicial abarca cinco medidas que son: la restitución, la compensación, la rehabilitación, la satisfacción y las garantías de no repetición. Por otra parte, las reparaciones en escenarios transicionales o de posconflicto se refieren a programas de medidas coordinadas con cobertura masiva.

En esta oportunidad se abordará el término desde una noción ecléctica, es decir haciendo referencia a una reparación de tipo jurídico y a que en ella se responda a los intentos de proporcionar beneficios directos y masivos a las víctimas; de acuerdo con su sentir, sus necesidades y a su contexto.

Para ello, en el caso de las comunidades afro, se debería responder a medidas concretas con estándares y alcances realistas y con orientación específica, un escenario interactivo, de tal suerte que cualquier persona que haga parte de un programa de reparaciones tuviera la posibilidad de participar en él. Un ejemplo sería lograr que se puedan establecer parámetros de reparación integral individual y colectiva a víctimas de violaciones de derechos humanos de la comunidad afrodescendientes a partir de varias experiencias en el sistema interamericano, desde una perspectiva de estándares, instrumentos de protección (derecho internacional) y programas (políticas públicas) de reparaciones con enfoque étnico.

De ahí que los programas de reparaciones en el marco de la justicia transicional no deberían diseñarse con base en la estructura de la reparación judicial como sucedió con la Ley 1448 de 2011, de Víctimas y Restitución de Tierras, debido a que se corre el riesgo de crear programas complejos, basados en medidas de muy amplio alcance 
que difícilmente se logran cumplir, especialmente en contextos de violaciones masivas de derechos humanos.

Esto significa que debe procurarse por lo menos, que los responsables de los hechos victimizantes rindan cuentas de sus actos, las reparaciones logren el reconocimiento de las víctimas como ciudadanos y agentes activos en su proceso, y la generación de confianza entre ellas y el Estado.

Con relación al derecho a la reparación, si en nuestro país se quiere que ésta sea realmente justa, adecuada y efectiva, tendrá que hacerse a través de mecanismos concretos, participativos, con enfoque diferencial y, sobre todo, realistas, que respeten los principios procesales fijados en las normas locales e internacionales, las realidades sociales y culturales de las víctimas y la dignidad de las personas que sufren esa condición, pues en muchísimos casos encontramos escenarios de reparaciones que en su máxima dimensión, se constituyen en una mera compensación, que para las necesidades del afectado termina siendo precaria, y en los demás aspectos relativos al resarcimiento, se convierten en un planteamiento puramente retórico y en una utopía. Por ejemplo el reconocimiento de calidad de victima que hace la Unidad de Reparación, a una adulta mayor, abuela de una adolescente que padece una discapacidad física y cognitiva, quienes llevan más de cuatro años reclamando su derecho a ser indemnizadas y no obstante la menor alcanzar su mayoría de edad esperando la ayuda y habérseles asignado un turno para pago, el plazo se venció y la UARV aduce que tiene hasta 10 años para hacerla efectiva, esto es cuando la señora fallezca ¿y no pueda disfrutarla?.

\section{PLANTEAMIENTO DEL PROBLEMA}

¿Cuál es la justificación legal, que, dentro del derecho a la justicia, sustente promover una efectiva reparación a los afrocolombianos víctimas del desplazamiento forzado en ocasión del conflicto armado en Colombia, desde una perspectiva de Etno reparación o con enfoque diferencial étnico?

La ley 1448 de 2011, contempla 28 principios procesales de Reparación y restauración de víctimas de desplazamiento forzado, entre los que se destacan los principios de dignidad, igualdad, buena fe, verdad, justicia, reparación, enfoque diferencial, Justicia transicional, entre otros. 
La justicia étnica como criterio de reparación de las víctimas del desplazamiento forzado en el marco del conflicto armado en Colombia

"Nos ocuparemos de los principios procesales de justicia y enfoque diferencial (COLÔMBIA, 2011) para resolver el problema jurídico planteado y entender, cuál es la justificación legal, que, dentro del derecho a la justicia, sustenta la necesidad de promover una efectiva reparación a los afrocolombianos víctimas del desplazamiento forzado en ocasión del conflicto armado en Colombia, desde una perspectiva de Etno reparación.

En primer término, el artículo 13, nos indica que

ENFOQUE DIFERENCIAL.

El principio de enfoque diferencial reconoce que hay poblaciones con características particulares en razón de su edad, género, orientación sexual y situación de discapacidad. Por tal razón, las medidas de ayuda humanitaria, atención, asistencia y reparación integral que se establecen en la presente ley, contarán con dicho enfoque.

El Estado ofrecerá especiales garantías y medidas de protección a los grupos expuestos a mayor riesgo de las violaciones contempladas en el artículo $3^{\circ}$ de la presente Ley tales como mujeres, jóvenes, niños y niñas, adultos mayores, personas en situación de discapacidad, campesinos, líderes sociales, miembros de organizaciones sindicales, defensores de Derechos Humanos y víctimas de desplazamiento forzado.

Para el efecto, en la ejecución y adopción por parte del Gobierno Nacional de políticas de asistencia y reparación en desarrollo de la presente ley, deberán adoptarse criterios diferenciales que respondan a las particularidades y grado de vulnerabilidad de cada uno de estos grupos poblacionales.

Igualmente, el Estado realizará esfuerzos encaminados a que las medidas de atención, asistencia y reparación contenidas en la presente ley, contribuyan a la eliminación de los esquemas de discriminación y marginación que pudieron ser la causa de los hechos victimizantes (COLÔMBIA, 2011).

A su vez, el artículo 24, sobre el derecho a la justicia, nos señala que

Es deber del Estado adelantar una investigación efectiva que conduzca al esclarecimiento de las violaciones contempladas en el artículo tercero de la presente Ley, la identificación de los responsables, y su respectiva sanción: Las víctimas tendrán acceso a las medidas de atención, asistencia y reparación contempladas en esta ley o en otros instrumentos legales sobre la materia, sin perjuicio de su ejercicio del derecho de acceso a la justicia (COLÔMBIA, 2011).

Partiendo del análisis de los instrumentos de derecho internacional y la jurisprudencia de la Corte Interamericana de Derechos humanos (Corte IDH), existe algunos criterios de reparación individual y colectiva para la población afrodescendiente víctima de violaciones a los derechos humanos. Para ello, importante identificar primigeniamente, factores de discriminación estructural como el no acceso a los derechos civiles, políticos, económicos, sociales, culturales, factores de discriminación racial 
(violencia epistémica), entre otros derechos vulnerados que se encuentran contemplados en la Declaración Americana de los Derechos y Deberes del Hombre y la Convención Interamericana, generando así herramientas jurídicas, de política pública y judiciales en relación a la verdad, justicia y reparación y garantías de no repetición para este grupo étnico en las Américas y el Caribe.

Acorde con las naciones unidas "Los afrodescendientes viven en muchos países del mundo, dispersos en la población local o formando comunidades. La mayor concentración puede encontrarse en América Latina y el Caribe, donde se estima que su número asciende a 150 millones de personas. Tanto los descendientes de los africanos transportados a las Américas durante la trata transatlántica de esclavos, hace muchas generaciones como los que se han trasladado más recientemente a esa región, a Europa y Asia, e incluso dentro del mismo continente africano, constituyen uno de los grupos más marginados. Son un grupo de víctimas concreto que continúan siendo discriminados como legado histórico de la trata transatlántica. Incluso los afrodescendientes, cuyos antepasados no han sido esclavos, sufren el racismo y la discriminación que todavía subsisten hoy día, muchas generaciones después de que se haya terminado el comercio de esclavos" (NACIONES UNIDAS, Oficina del Alto Comisionado, 2017)

La población afrodescendiente en el hemisferio es producto de la trata trasatlántica que estableció la institución de la esclavitud; millones de descendientes de africanos (tribus, grupos étnicos) fueron apartados de sus legados culturales, de la vida en sí misma, para ser transportados a un nuevo continente como fuerza de trabajo (aperos parlantes), sin reconocerles la condición de seres humanos, no eran entonces personas, por lo tanto, tampoco sujetos de derechos. El "mercado" de esclavos se estableció en puertos firmes y también en innumerables islas en el Caribe, el nuevo legado de África en América forjó nuevos sustentos culturales, idiomas (lenguas), formas de relacionamiento, religiosidad, normas consuetudinarias, en otras palabras reprodujeron sus estructuras “clánicas”, de organización comunitaria, jurídica y territorial como diáspora Africana; es por esta razón que en la actualidad existen más de 150 millones de personas (CIDH, 2011, 6), cifra que equivale aproximadamente al 30\% de la población total en las Américas. Esta población cuenta con una idiosincrasia propia, costumbres, prácticas, territorialidad, lengua, patrimonio (material e inmaterial), artes y saberes que la diferencia del resto de la población, como un grupo étnico sui géneris en los Estados en donde coexiste la presencia afrodescendiente. 
La justicia étnica como criterio de reparación de las víctimas del desplazamiento forzado en el marco del conflicto armado en Colombia

Por ello, es importante revisar las injusticias históricas respecto a la diáspora africana desde el componente actual, que evidencia como los efectos negativos de los errores históricos en contra de la población afrodescendiente han generado causas estructurales de discriminación y desigualdad, razón por la que se puede sostener que las injusticias históricas persisten hoy y deben ser objeto de reparación.

En América y el Caribe dadas las dinámicas de desarrollo y condiciones históricas que se han presentado en las relaciones sociales por diferentes circunstancias, la población afrodescendiente ha visto vulnerados sus derechos como personas por diversas causas que van desde factores de discriminación étnico -racial, desconocimiento de territorios ancestrales, carencia de derechos civiles, políticos, económicos, sociales, culturales y ambientales unido a factores conexos y subyacentes como la criminalización, exclusión social, el no acceso a bienes y servicios, en unidad con la explotación irracional de los recursos naturales en sus territorios, sumado a ello las afectaciones diferenciadas con ocasión de los conflictos armados internos, en los diferentes Estados se puede enunciar que estamos ante una vulneración sistemática de los derechos humanos de la población afrodescendiente.

Las víctimas de violaciones a derechos humanos cuentan con la prerrogativa que le asiste a los Estados en su obligación de reparar integralmente, con ocasión de los daños (materiales, morales, a la vida en relación y espirituales -pueblos étnicos-), sufridos en razón a la vulneración o lesión de sus derechos amparados por el ordenamiento jurídico interno y el derecho internacional de los derechos humanos (principios, declaraciones, convenciones). La reparación además debe ser restaurativa, lo que implica no regresar al estado anterior a la vulneración de los derechos, en la restitución de los mismos, sino ir más allá y cambiar las condiciones anteriores a la transgresión de los derechos, es decir, mejorar las condiciones de vida de los individuos, teniendo presente el hecho victimizante (violación del derecho humano) y la afectación provocada por esta acción u omisión contraria a derecho, en una dimensión individual y colectiva a los integrantes del grupo étnico (OEA, 1969)

La reparación integral a víctimas tiene un sentido sanador, reconciliador, como también el reconocimiento a la vulneración del derecho, respeto por la dignidad humana, así mismo; la declaración por parte del Estado de los hechos victimizantes y de su responsabilidad en la no protección y garantía de los derechos humanos de las personas bajo su tutela; esto desde un punto de vista institucional o gubernamental. 


\section{INSTRUMENTOS DE DERECHO INTERNACIONAL Y ESTÁNDARES DE PROTECCIÓN A LA POBLACIÓN AFRODESCENDIENTE.}

$\mathrm{Al}$ realizar un recorrido por el derecho internacional y los instrumentos en el sistema de derechos humanos, se observa que no existen convenios, tratados, convenciones, específicas para la prevención, protección y garantía de los derechos específicos de la población afrodescendiente como grupo étnico en el hemisferio Americano, es por ello, que en este acápite se relacionarán algunos instrumentos de derecho internacional, que podemos indicar que son atribuibles a la población afrodescendiente por ser sujetos de derecho en el plano internacional. De igual forma el Sistema Americano en su análisis holístico de los instrumentos de protección los adopta en pro de un mayor marco de protección y amparo de los derechos en América y el Caribe.

$\mathrm{Al}$ realizar un recorrido por el derecho internacional y los instrumentos en el sistema de derechos humanos, se observa que no existen convenios, tratados, convenciones, específicas para la prevención, protección y garantía de los derechos específicos de la población afrodescendiente como grupo étnico en el hemisferio Americano, es por ello, que en este acápite se relacionarán algunos instrumentos de derecho internacional, que podemos indicar que son atribuibles a la población afrodescendiente por ser sujetos de derecho en el plano internacional. De igual forma el Sistema Americano en su análisis holístico de los instrumentos de protección los adopta en pro de un mayor marco de protección y amparo de los derechos en América y el Caribe.

Dentro los instrumentos podemos señalar la Convención para la Prevención y la Sanción del Delito de Genocidio. Establece el concepto de genocidio indicando que es cualquiera de los actos, perpetrados con la intención de destruir, total o parcialmente, a un grupo nacional, étnico, racial o religioso.

La Convención Internacional sobre la Eliminación de todas las Formas de Discriminación Racial, acuña el término discriminación racial. Esta denotará toda distinción, exclusión, restricción o preferencia basada en motivos de raza, color, linaje u origen nacional o étnico, que tenga por objeto o por resultado anular o menoscabar el reconocimiento, goce o ejercicio, en condiciones de igualdad, de los Derechos Humanos y libertades fundamentales en las esferas políticas, económicas, social, cultural o en cualquier otra esfera de la vida pública. 
La justicia étnica como criterio de reparación de las víctimas del desplazamiento forzado en el marco del conflicto armado en Colombia

La Declaración y el Programa de Acción de Durban, abordó diferentes temas, entre ellos: Establecimiento de remedios, recursos, vías de reparación y otras medidas eficaces en los ámbitos nacional, regional e internacional, estrategias para lograr una igualdad plena y efectiva que abarquen la cooperación internacional y el fortalecimiento de las Naciones Unidas y otros mecanismos internacionales en la lucha contra el racismo, la discriminación racial, la xenofobia y las formas conexas de intolerancia, y su seguimiento.

Consultas informales del Comité Preparatorio Ginebra, 15-16 de enero de 2001. La Declaración y Plan de Acción de Santiago, incorporó algunos lineamientos respecto a responsabilidad de los estados y el deber de reparar, señalando los remedios, reparación, administración de justicia, crímenes contra la humanidad y derecho humanitario, se identifican factores de vulneración de derechos propios de la trata transatlántica y el sistema esclavista, siguiendo con la discriminación racial, la xenofobia, formas conexas de intolerancia y la precariedad en el acceso a derechos económicos, sociales y culturales.

Los instrumentos internacionales antes mencionados enmarcan los derechos específicos de las personas de descendencia africana, en el ámbito de derechos humanos, derecho internacional humanitario y acciones de no discriminación, todas encaminadas a la adopción de medidas especiales por parte de los Estados en materia de amparo de derechos en su ámbito general y particular, así mismo el establecimiento de acciones constitucionales, legales y afirmativas conducentes a salvaguardar la integridad étnica y cultural de los afrodescendiente al interior de los países que acogieron estos estándares de protección a los afros, en igual forma se insta a los otros Estados a acoger disposiciones internas sobre derechos de la población afrodescendiente.

De otro lado existen Iniciativas contra el Racismo y la Discriminación Racial ${ }^{2}$ cuya finalidad es avanzar hacia un amparo de derechos, que van desde conmemoración de días hasta espacios académicos de discusión.

\section{MECANISMOS DE PROTECCIÓN CONTRA LA DISCRIMINACIÓN} RACIAL.

Existen algunos mecanismos de protección contra la discriminación racial, que son: a) Comité para la eliminación de la discriminación racial, que es un órgano de expertos que realizan el examen a los Estados respecto a las medidas legislativas, 
judiciales, administrativas o de otra índole que hayan adoptado en pro de la salvaguarda, protección y amparo de los derechos contemplados en la Convención; Así mismo presenta informe a la Asamblea general de ONU con sugerencias y recomendaciones para el cumplimiento de éste instrumento internacional (artículos 8-9, Convención Internacional sobre la Eliminación de todas las Formas de Discriminación Racial).

El Comité en el marco de sus funciones y competencias recibe las denuncias de los particulares (personas o grupos) y examina a los Estados en el marco de la Convención, tiene conocimiento de casos de discriminación racial y de las violaciones de la Convención, por medio de los informes periódicos presentados por los Estados sobre la Eliminación de todas las Formas de Discriminación Racial y presenta observaciones, alertas tempranas, denuncias entre Estados, denuncias artículo 14 de la Convención. En determinadas circunstancias también puede explorar las denuncias o comunicaciones de los particulares que indiquen ser víctimas en el marco de la Convención y de un Estado parte que haya reconocido la plena competencia del Comité respecto a personas sujetas a su jurisdicción.

El Comité como órgano de tratado, se constituye en una herramienta para el seguimiento al amparo de los derechos de la diáspora africana, ha sido criticada su labor por no contar con mecanismos más coercitivos respecto a la obligación que le asiste a los estados de cumplir con la Convención Internacional sobre la Eliminación de todas las Formas de Discriminación Racial, por su facultad de presentar observaciones, sugerencias y recomendaciones. b) Relatoría especial sobre formas contemporáneas de racismo, discriminación racial, xenofobia y formas conexas de intolerancia. Esta realiza una supervisión y emite informes relativos a su mandato, es un experto designado por el Consejo de Derechos Humanos de ONU, a través de sus informes, visitas de investigación y llamamientos quien expone las circunstancias de violación del principio de no discriminación racial.

En el orden interno colombiano, tenemos la ley 70 de 1993 que desarrolla el artículo 55 transitorio de la Constitución Nacional, el cual ordenaba al gobierno Nacional expedir una ley que les reconociera a las comunidades negras que han venido ocupando tierras baldías en las zonas rurales ribereñas de los ríos de la Cuenca del Pacífico, de acuerdo con sus prácticas tradicionales de producción, el derecho a la propiedad colectiva sobre las áreas que habría de demarcar la misma ley. El artículo 3 de la ley 70, establece que el precepto se fundamenta en los siguientes principios: 
La justicia étnica como criterio de reparación de las víctimas del desplazamiento forzado en el marco del conflicto armado en Colombia

Art. 3. 1). El reconocimiento y la protección de la diversidad étnica y cultural y el derecho a la igualdad de todas las culturas que conforman la nacionalidad colombiana. 2). El respeto a la integralidad y la dignidad de la vida cultural de las comunidades negras. 3). La participación de las comunidades negras y sus organizaciones sin detrimento de su autonomía, en las decisiones que las afectan y en las de toda la Nación en pie de igualdad, de conformidad con la ley. 4). La protección del medio ambiente atendiendo a las relaciones establecidas por las comunidades negras con la naturaleza" (COLÔMBIA, 1993).

Por su parte, y en relación con la jurisprudencia nacional, encontramos entre otras la Sentencia T-025 de 2004, en la que nuestra Corte Constitucional expresó: "En razón de esta multiplicidad de derechos constitucionales afectados por el desplazamiento, $\mathrm{y}$ atendiendo a las aludidas circunstancias de especial debilidad, vulnerabilidad e indefensión en la que se encuentran los desplazados, la jurisprudencia constitucional ha resaltado que éstos tienen, en términos generales, un derecho a recibir en forma urgente un trato preferente por parte del Estado. Este derecho al trato preferente constituye, en términos de la Corte, el punto de apoyo para proteger a quienes se hallan en situación de indefensión por el desplazamiento forzado interno", y debe caracterizarse, ante todo, por la prontitud en la atención a las necesidades de estas personas, ya que "de otra manera se estaría permitiendo que la vulneración de derechos fundamentales se perpetuara, y en muchas situaciones, se agravara.

Luego la misma corporación emitió el Auto 005 del 26 de enero de 2009, para proteger los derechos fundamentales de la población afrodescendiente víctima del desplazamiento forzado, al constatar que

(i) no son tratados como sujetos de especial protección constitucional; (ii) que sus derechos fundamentales están siendo masiva y continuamente desconocidos y que (iii) la política pública de atención carece de un enfoque integral diferencial, cuya incorporación en la prevención, protección y atención, es una obligación para las autoridades de naturaleza tanto constitucional como internacional. Por lo anterior, la Corte dictó órdenes concretas y con plazos perentorios al Gobierno Nacional, con el fin de que los programas tuvieran en cuenta las particularidades del desplazamiento que padece la población afrocolombiana y para que se adoptaran medidas particulares encaminadas a la protección efectiva de los derechos colectivos de estas comunidades (COLÔMBIA, 2009)

\section{RESPONSABILIDAD INTERNACIONAL DE LOS ESTADOS POR VIOLACIONES A LOS DERECHOS HUMANOS}


En materia de responsabilidad de los Estados y la reparación por las obligaciones contraídas por estos en los tratados y demás instrumentos de derecho internacional de protección de los derechos humanos, encontramos en el ámbito universal diferentes herramientas jurídicas que incorporan la responsabilidad y la obligación de los Estados a reparar, por hechos ilícitos internacionalmente considerados, entre estos, las violaciones a los derechos humanos, entre los que se incluyen todos aquellos que se desprenden del conflicto armado, indicando además que sus víctimas tienen derecho a la verdad, justicia, reparación y garantías de no repetición. Uno de estos instrumentos es la Resolución 1503 de 1970 de la Organización de Naciones Unidas -ONU, que nos enmarca la obligación respecto a la protección de los derechos; la Asamblea General de las Naciones Unidas, deliberó sobre la responsabilidad internacional del Estado por hechos Ilícitos (AG/56/83), señalando la obligación de reparar, especialmente en su artículo $31^{3}$.

De igual forma, la Resolución 60/147, aprobada por la Asamblea General el 16 de diciembre de 2005, incorporó los principios y directrices básicos sobre el derecho de las víctimas de violaciones manifiestas de las normas internacionales de derechos humanos y de violaciones graves del derecho internacional humanitario a interponer recursos y obtener reparaciones.

Además, el Estado es responsable por un hecho ilícito de derecho internacional cuando se presentan varias circunstancias: a) "acción, acto u omisión atribuible al Estado es decir, por un órgano agente, representante suyo- propios hechos o en unidad con terceros, cause daño antijurídico, afectación o vulneración de derechos" (CORTE INTENACIONAL DE JUSTICIA, 2002), b) acción, acto u omisión que constituya una violación o se encuentre tipificado como tal en el derecho internacional ${ }^{4}$. Todo esto trae consigo la obligación de reparar por el hecho ilícito, afectación, vulneración de los derechos e igualmente el deber de suspender las acciones, hechos o abstenerse de realizar, y en su defecto adoptar medidas para que cese el acto tipificado como violatorio del derecho internacional o la vulneración de los derechos humanos.

En el ámbito americano observamos que la responsabilidad de los Estados, en el marco de la Convención Americana de Derechos Humanos, el artículo $1^{\circ}$ señala la Obligación de Respetar los Derechos. Por su parte el artículo 1.1 incorpora la obligación de Respetar y Garantizar, en primera medida $i$. Respetar, implica las obligaciones de no hacer, la de ii. Garantizar, contempla la obligación de prevenir, investigar y sancionar; 
La justicia étnica como criterio de reparación de las víctimas del desplazamiento forzado en el marco del conflicto armado en Colombia

estas son medidas, que además implica para los estados la iii. Debida Diligencia; en este mismo orden de ideas el artículo 2 de la Convención establece otra responsabilidad y es la de vi. Adoptar Disposiciones de Derecho Interno, existe además la Responsabilidad Reforzada, en casos de poblaciones en estado de vulnerabilidad (mujeres, adulto mayor, orientación sexual, grupos étnicos, discapacidad) (OEA, 1969).

De igual forma, la Responsabilidad Agravada respecto a los crímenes y la necesidad de reparaciones (CORTE INTERAMERICANA DE DERECHOS HUMANOS, 2003). También se genera la obligación de reparar cuando el Estado Reconoce su responsabilidad en la violación de los derechos (Reconocimiento de Responsabilidad). En síntesis, le asiste a los Estados el deber y la obligación de reparar en cuatro circunstancias: cuando incumple con sus obligaciones de respetar, garantizar, al no realizar acciones de debida diligencia para el amparo y protección de los derechos y cuando no se adoptan disposiciones o medidas internas para la preservación de los derechos humanos de manera diferencial, máxime cuando es el propio Estado quien vulnera los derechos y lo admite de forma explícita.

El origen de la responsabilidad por actos de terceros o particulares, señala que si bien los Estados son responsables por hechos ilícitos atribuibles a los mismos por su acción u omisión (respetar, garantizar, adoptar) y por un agente con acciones desplegadas en el ejercicio de su poder jurisdiccional sobre los habitantes sometidos a su derecho interno, también le asiste a los Estados la responsabilidad por terceros o particulares, atendiendo a los hechos ilícitos internacionalmente considerados, esta tercera forma de responsabilidad ocurre cuando teniendo el poder de garante, no se realizaron acciones para evitar la vulneración de los derechos humanos. Lo mismo ocurre cuando cohonestan agentes del Estado y terceros al realizar actos punibles en el marco del derecho penal nacional, e internacional y violatorios de los instrumentos de protección de los derechos humanos, finalmente, cuando los Estados omiten su obligación de garantizar derechos a terceros lo que ocasiona la vulneración a sus derechos como personas. El Estado debe actuar para prevenir y reprimir actos ilícitos al derecho internacional y de violación de derechos, atendiendo su deber de garantizarlos, de lo contrario genera responsabilidad internacional, y por lo tanto debe reparar.

\section{VIOLACIONES A LOS DERECHOS HUMANOS QUE DEBEN SER OBJETO DE REPARACIONES.}


Se trata de todas aquellas violaciones, transgresiones, incumplimientos, la no adopción de medidas, la omisión a la garantía de los derechos civiles, políticos, económicos, sociales, culturales y ambientales, discriminación racial, de género y demás disposiciones ratificadas por los Estados en los tratados, convenciones, pactos de derechos humanos a los cuales no hayan establecido restricciones a sus efectos o limitantes para su ejercicio o aplicación en el ordenamiento jurídico interno; en segundo lugar se debe señalar el terrorismo, despojo de tierras y territorios, actos de barbarie, plantar minas antipersona-municiones sin explotar-MUSE-; en tercer lugar, las lesiones personales, desaparición forzada, asesinatos cometidos por el Estado, estas más relacionadas con el DIH y, por último, todas aquellas manifestaciones, acciones y medidas que impliquen discriminación por discapacidad, xenofobia y racismo.

Para los grupos étnicos la violación de los derechos humanos implica, la vulneración a su historia misma, cultura, identidad, supervivencia como pueblo, la vulneración de sus derechos territoriales y específicos, como el derecho a la consulta previa, libre e informada, el derecho propio, desconocimiento de las formas de gobernanza, implantación de modelos extractivos en territorios ancestrales de las comunidades, megaproyectos en tierras de grupos étnicos, imposición de monocultivos, confinamiento de población, el no acceso a los bienes y servíos. Por otro lado, también se toma como violación de los derechos humanos lo establecido en el Estatuto de Roma de la Corte Penal Internacional Naciones Unidas 1998, artículos 6, 7 y 8, referentes al genocidio, crimen de lesa humanidad y de guerra respectivamente.

En general se considera violación a los derechos humanos, aquellos actos que vulneran los amparos y normas contempladas en el derecho interno de los Estados y en los instrumentos internacionales ratificados por estos, a quienes se les señala del no cumplimiento de sus obligaciones de garantizar, proteger y adoptar disposiciones para evitar la vulneración de los derechos de los ciudadanos, así mismo por las infracciones al DIH, por acción u omisión en su deber legal para que las conductas de hechos internacionalmente ilícitos no ocurran.

\section{CONCEPTO DE VÍCTIMA DE VIOLACIONES DE LOS DERECHOS HUMANOS}


La justicia étnica como criterio de reparación de las víctimas del desplazamiento forzado en el marco del conflicto armado en Colombia

No existe un concepto unificado o uniforme de víctima, dado los riesgos que se corren en dejar vulneraciones $\mathrm{u}$ afectaciones por fuera de la categoría, pero sí existen elementos que podemos señalar como integrantes del concepto de víctima.

De acuerdo con la Oficina del Alto Comisionado de Las Naciones Unidas para los Derechos Humanos, se puede entender por víctimas toda persona que haya sufrido daños, individual o colectivamente, incluidas lesiones físicas o mentales, sufrimiento emocional, pérdidas económicas o menoscabo sustancial de sus derechos fundamentales, como consecuencia de acciones u omisiones que constituyan una violación manifiesta de las normas internacionales de derechos humanos o una violación grave del derecho internacional humanitario. Cuando corresponda, y en conformidad con el derecho interno, el término «víctima» incluirá también a la familia inmediata o las personas a cargo de la víctima directa y a las personas que hayan sufrido daños al intervenir para prestar asistencia a víctimas en peligro o impedir su victimización. Una persona será considerada víctima con independencia de si el autor de la violación ha sido identificado, aprehendido, juzgado o condenado y de la relación familiar que pueda existir entre el autor y la víctima (NACIONES UNIDAS, Instrumentos del estado de derecho para sociedades que han salido de un conflicto, 2008, p. 18-19).

Se puede indicar que una víctima es toda aquella persona individual y colectiva, que ha sufrido un daño, afectación, vulneración de sus derechos humanos o con ocasión de las infracciones al derecho internacional humanitario, por acción u omisión del Estado en sus deberes derivados del ordenamiento jurídico interno o de los instrumentos de derecho internacional ratificados o adheridos; por lo tanto, tiene la obligación de reparar.

Las siguientes son algunas de las modalidades de víctimas: a) Individual: natural y jurídica. b) Colectiva: la víctima colectiva se refiere a integrantes de una comunidad, grupo étnico o familias, que sufren la vulneración de sus derechos, un daño o perjuicio, acciones victimizantes, conductas reiterativas o sistemáticas, acciones de daño, limitación al ejercicio de sus derechos; cuando se trata de grupos étnicos en este caso la población afrodescendiente, al hablar de colectivo no implica únicamente que el impacto o la vulneración sea a un número plural de personas con una misma conducta tipificada en el derecho internacional como ilícita, sino que el daño se produzca a la cultura, formas organizativas o a su esencia como población. En Colombia se ha identificado también a la víctima individual con efecto colectivo, dentro de la cual se destaca aquella conducta ilícita contra un miembro de la comunidad que tiene relevancia 
social, cultural, étnica (mayores, sabios, curanderos, lideres, etc.), religiosa o política, que ocasiona daño al individuo o su familia, pero los efectos son para toda la comunidad ya que producto de esta acción se generan concomitantemente otras vulneraciones. Una víctima plural son varias personas que sufrieron un daño, estas no tienen en común derechos, bienes jurídicos tutelados o los hechos no se producen con ocasión de afectar un colectivo si no generar un impacto con la victimización o con la acción, la diferencia entre una y otra radica en el bien jurídico protegido y afectado por el hecho ilícito o licito que vulnera. Las víctimas colectivas pueden ser determinadas, es decir, identificables estas se su pone su existencia, pero se dificulta su individualización; al momento de reparar si el conjunto de las víctimas no se halla identificado lo importante es que sean determinables territorialmente, geográficamente o étnicamente. c) El territorio como víctima: El territorio se constituye en víctima por los daños ambientales, ecológicos y la inseguridad legal del mismo. Esta experiencia de víctima colectiva se puede observar en la Ley de Víctimas y Restitución de Tierras (Ley 1448 de 2011) y Decreto ley 4633 de 2011, en el Estado de Colombia, para los grupos étnicos afrodescendientes, pueblos indígenas y Rom (gitanos), el territorio bajo sus cosmovisiones es un derechos fundamental reconocido constitucional y legalmente, por ello si con ocasión de una vulneración a los derechos humanos e infracciones al DIH se produce un daño en sus territorios ancestrales este también es considerado víctima. Para los pueblos indígenas el territorio requiere un proceso de ritual de sanación y armonización de las dimensiones espirituales y terrenales, y su reparación se ubica en términos de sanación territorial, seguridad jurídica, constitución de territorios colectivos, la no intromisión Estatal en los mismos atendiendo a la autodeterminación de los pueblos del Pacto de derechos civiles y políticos.

El territorio no es únicamente donde se habita, es todo aquello de lo que de él emana o se desprende, las actividades, la cultura, el agua, el aire y las relaciones que se tejen alrededor de él. También el territorio es víctima con la explotación de recursos naturales, megaproyectos, fumigaciones de cultivos de uso ilícito (drogas), contaminación de fuentes hídricas, despojo de tierras y usurpación.

\section{EJEMPLOS RELEVANTES DE CONDENAS CONTRA ESTADOS POR VIOLACIÓN DE DERECHOS HUMANOS, DE LA POBLACIÓN AFRODESCENDIENTE}


La justicia étnica como criterio de reparación de las víctimas del desplazamiento forzado en el marco del conflicto armado en Colombia

Dos emblemáticos casos en que dos Estados miembros del Sistema Interamericano de Protección de Derechos humanos, fueron declarados responsables por violación de derechos humanos, de la población afro descendiente.

a) Caso de las comunidades afrodescendientes desplazadas de la cuenca del río cacarica (operación génesis) vs. Colombia, sentencia de 20 de noviembre de 2013.

Este caso encierra violaciones a los derechos humanos e infracciones al derechos internacional humanitario, por las acciones y omisiones del ejército colombiano en una operación militar, en la que también se vieron inmersos a través de incursiones armadas grupos al margen de la ley denominados paramilitares, con lo que se vieron violados y afectados los derechos de la población afrodescendiente de la cuenca del río Cacarica y el Bajo Atrato en el departamento de Chocó, los derechos inmersos son tanto individuales: vida, circulación, integridad, acceso a la justicia como colectivos, entre ellos la seguridad respeto al territorio y el aprovechamiento de los recursos naturales. La Corte Interamericana de Derechos humanos Condenó al Estado Colombiano por sus omisiones en este caso. (OPERACION GENESIS vs. COLOMBIA, 2013)

La Corte declaró que el Estado es responsable en este caso por dos razones fundamentales: de un lado, por haber incumplido con su obligación de garantizar los derechos a la integridad personal de los pobladores, particularmente en dos situaciones: de un lado, con respecto a los desplazamientos forzados que se dieron por acción de los grupos paramilitares en el marco de la Operación Cacarica; de otro, por el incumplimiento de sus obligaciones de garantizar la asistencia humanitaria y un retorno seguro a sus tierras.

Además, la CIDH concluyó que el Estado es responsable por la violación de los derechos a la vida y a la integridad personal, en perjuicio del señor Marino López Mena por el incumplimiento de sus obligaciones de prevención, protección e investigación, así como por la violación del derecho a la integridad personal en perjuicio de sus familiares.

A su vez, la Corte estableció que el Estado es responsable por la violación de los derechos de niños y niñas, por no haber desarrollado las acciones positivas suficientes a su favor en un contexto de mayor vulnerabilidad, en particular mientras estuvieron 
alejados de sus territorios ancestrales, período en que se vieron afectados por el hacinamiento y la falta de acceso a educación, salud y alimentación adecuada.

b) Caso Nadege Dorzema y otros vs. República dominicana, sentencia de 24 de octubre de 2012.

En el presente se encuentran inmersos ciudadanos del Estado haitiano y agentes de la fuerza pública de Republica dominicana, que dispararon a un transporte que conducía a migrantes haitianos, lo que dejó como saldo siete personas asesinadas y al menos 10 heridas, en unidad a actos de corrupción por la solicitud de dineros a los afectados, en lo que ha sido denominado como uso excesivo de la fuerza armada contra haitianos.

En estas actuaciones se encuentran inmersas circunstancias relativas o conexas a formas contemporáneas de racismo, discriminación racial, xenofobia y formas conexas de intolerancia, discriminación a minorías nacionales, perfiles raciales y prototipos raciales de imputabilidad. La Corte Interamericana, también Condenó en este caso al Estado de la República dominicana. (NADEGE DORZEMA Y OTRS vs. RRECPUBLICA DOMNICANA, 2012)

La Corte declaró: Que el Estado era responsable por la violación del derecho a la vida, reconocido en el artículo 4.1 de la Convención Americana sobre Derechos Humanos, en relación con el artículo 1.1 de la misma, - Que el Estado era responsable por la violación del derecho a la integridad personal, reconocido en el artículo 5.1 de la Convención Americana sobre Derechos Humanos, en relación con el artículo 1.1 del mismo instrumento.- Que el Estado era responsable por la violación de los derechos a la integridad personal reconocido en el artículo 5.1 de la Convención Americana sobre Derechos Humanos, en relación con el artículo 1.1 del mismo instrumento.- Que el Estado era responsable por la violación del derecho a la libertad personal, reconocido en el artículo 7.1, 7.2, 7.3, 7.4, 7.5 y 7.6 de la Convención Americana sobre Derechos Humanos, en relación con el artículo 1.1 de la misma. - Que el Estado es responsable por la violación de los derechos a las garantías judiciales y de libre circulación, reconocidos en los artículos 8.1 y 22.9 de la Convención Americana sobre Derechos Humanos, en relación con el artículo 1.1 del mismo instrumento.

Como se ha explicado, desde tiempos ancestrales, la población afrodescendiente ha sufrido estructuralmente situaciones de discriminación y desigualdad R. Fac. Dir. UFG, v. 41, n.2, p.47-68, maio / ago. 2017 
La justicia étnica como criterio de reparación de las víctimas del desplazamiento forzado en el marco del conflicto armado en Colombia

que incluso persiste hasta hoy, las cuales han potenciado condiciones de vulnerabilidad, permitiéndoles sufrir un proceso de victimización sistemática, que por falta de políticas públicas inclusivas, les hace presa fácil de los actores violentos y de una constante violación de sus derechos humanos, vulneraciones que se expresan desde factores de discriminación étnico -racial, desconocimiento de territorios ancestrales, carencia de derechos civiles, políticos, económicos, sociales, culturales y ambientales, la criminalización, exclusión social, el no acceso a bienes y servicios, en unidad con la explotación irracional de los recursos naturales en sus territorios, sumado a ello las afectaciones diferenciadas con ocasión de los conflictos armados internos, con lo cual se les ha apartado de su legado cultural. Ello justifica que, a la hora de reconocerles y aplicárseles principios procesales de reparación, el criterio de justicia permita que dicha satisfacción se realice desde una perspectiva étnica o con un enfoque diferencial para la comunidad afrocolombiana.

\section{CONCLUSIONES}

Se calcula que en Colombia 5,5 millones de hectáreas de tierra es la extensión aproximada de la que muchas personas han sido despojadas y es la misma proporción que sería objeto de políticas de restitución. Estar áreas, comparadas con las cifras sobre extensiones que han sido tituladas colectivamente a grupos étnicos, ofrece una primera aproximación al peso relativo de la justicia transicional y la justicia étnica colectiva como fuentes de distribución y redistribución de tierra en nuestro país. Así entonces, el desafío de restituir las tierras y los territorios despojados y de reparar a las víctimas adquiere características especiales cuando los primeros son territorios colectivos y las segundas son comunidades cuya supervivencia cultural depende del goce efectivo de dichos territorios.

El procedimiento para determinar e implementar las medidas de reparación con enfoque diferencial para la población afro, tiene que ser guiado por los principios de reconocimiento y reivindicación del grupo étnico como colectividad. Esto comprende al menos los siguientes cuatro criterios, los cuales están estrechamente interrelacionados: 1) A lo largo de todo el proceso de determinación de las medidas de reparación, es necesario consultar con el grupo étnico que, a su vez, debe jugar un importante papel su implementación; 2) Las medidas de reparación tienen que respetar la identidad cultural particular del grupo étnico; 3) las etnoreparaciones siempre deben tomar en cuenta la 
dimensión colectiva de las violaciones y las medidas de reparación; 4) para que las reparaciones sean eficaces, su determinación debe partir de lo específico y debe ser enfocada hacia la satisfacción de las necesidades del grupo étnico.

Por eso, para que haya una verdadera JUSTICIA y una reparación con enfoque diferencial, a la hora de hacer una ponderación de derechos individuales y étnicos para reparar con respecto a la población afrodescendiente, deberán tenerse en cuenta los siguientes aspectos: a) territorio de uso y ocupación ancestral, b) saneamiento territorial, c) implementación y apoyo económico para actividades de subsistencia como son la agricultura, la pesca, la caza y la recolección de productos d) Apoyo y acompañamiento para la explotación de los recursos naturales, e) Respeto por la conservación de su derecho propio, identidad cultural, costumbres y tradiciones, f) autoridad étnica, esto es, respeto y reconocimiento de las autoridades étnicas, formas organizativas y de representación g) conservación y perfeccionamiento de la medicina tradicional, h) Propiciar foros en universidades e instituciones educativas, para discutir el tema e informar sobre su importancia a los diversos sectores de la sociedad Colombiana, h) Que en dichos territorios, se garantice la presencia parmente del Estado y algunas de sus instituciones, para asegurar así que las comunidades puedan volver a sus territorios sin el temor de ser revictimizadadas u obligadas a salir nuevamente de ellos.

Así mismo, se deben aplicar medidas tendientes a mitigar las afectaciones a los derechos territoriales, ambientales y ecosistemas, las cuales se encuentran en el marco de la restitución, como la titulación colectiva, adjudicación, saneamiento de las tierras, restitución de los derechos colectivos, restitución territorial, restauración eco sistémica, rehabilitación de pasivos ambientales, monitoreo de recursos ambientales y ecosistemas. En cuanto a medidas de indemnización por los daños ambientales pueden encaminarse a la ejecución de obras, adopción de medidas de seguridad ambiental, compensación territorial tendientes a recuperar el proyecto de vida de las comunidades y pueblos, y por último las medidas de rehabilitación, dirigidas a la recuperación de la salud (humanaanimal), armonización territorial, recuperación de ecosistemas, recuperación paisajística.

Sólo así podría pensarse en la aplicación de una verdadera justicia y en consecuencia acuñar un importante ingrediente para alcanzar una efectiva paz estable y duradera. 
La justicia étnica como criterio de reparación de las víctimas del desplazamiento forzado en el marco del conflicto armado en Colombia

\section{REFERÊNCIAS}

COLOMBIA, Congreso de la República. Ley 70 de 1993. Disponible: <http://www.alcaldiabogota.gov.co/sisjur/normas/Norma1.jsp?i=7388>. Consulta em 01 de junio de 2017.

COLOMBIA, Congreso de la República. Ley 1448 de 2011. Disponible en: <http://www.alcaldiabogota.gov.co/sisjur/normas/Norma1.jsp?i=43043>. Consulta em 01 de junio de 2017.

COLOMBIA, Corte Constitucional, Auto 005 del 26 de enero de 2009, Magistrado ponente Manuel José Cepeda Espinosa. Disponible en: <http://www.corteconstitucional.gov.co/relatoria/autos/2009/a005-09.htm>. Consulta em 01 de junio de 2017.

COLOMBIA, Corte Constitucional. Sentencia T-025 de 2004, Magistrado Ponente Manuel José Cepeda Espinosa, expediente T-653010. Disponible en: <http://www.corteconstitucional.gov.co/relatoria/2004/t-025-04.htm>. Consulta em 01 de junio de 2017.

COMISIÓN INTERAMERICANA DE DERECHOS HUMANOS. La situación de las personas afrodescendientes en las Américas. (2011). Obtenido de Disponible en: $<$ http://www.acnur.org/fileadmin/scripts/doc.php?file=fileadmin/Documentos/BDL/201 2/8311>. Consulta em 01 de junio de 2017.

CORTE INTERAMERICANA DE DERECHOS HUMANOS. Caso Nadege Dorzema Y Otros Vs. Republica Dominicana 24 de octubre de 2012. Disponible em: <http://www.corteidh.or.cr/docs/casos/articulos/seriec_251_esp.pdf>. Consulta em $01 \mathrm{de}$ junio de 2017.

CORTE INTERAMERICANA DE DERECHOS HUMANOS Operación Génesis vs. Colombia 20 de noviembre de 2013. Disponible en: <http://www.corteidh.or.cr/docs/casos/articulos/seriec_270_esp.pdf >. Consulta em $01 \mathrm{de}$ junio de 2017.

CORTE INTERAMERICANA DE DERECHOS HUMANOS. Caso Myrna Mack Chang vs. Guatemala, 25 de noviembre de 2003. Disponible en: <http://www.corteidh.or.cr/docs/casos/articulos/seriec_101_esp.pdf >. Consulta em $01 \mathrm{de}$ junio de 2017.

CORTE INTERNACIONAL DE JUSTICIA. Caso Congo vs Bélgica 2002, orden de detención de 11 de abril 2010. Disponible en: <https://www.dipublico.org/cij/doc/136.pdf>. Consulta em 01 de junio de 2017.

NACIONES UNIDAS, Oficina del Alto Comisionado para los Derechos Humanos. Instrumentos Del Estado De Derecho Para Sociedades Que Han Salido De Un Conflicto (2008). Disponible en: <http://www.ohchr.org/Documents/Publications/ReparationsProgrammesSP.pdf >. Consulta em 01 de junio de 2017. 
NACIONES UNIDAS, Oficina del Alto Comisionado para los Derechos Humanos. Afrodescendientes. Disponible en: <http://www.un.org/en/events/africandescentdecade/assets/pdf/PAD_Spanish.pdf > Consulta em 01 de junio de 2017

ORGANIZACIÓN DE LOS ESTADOS AMERICANOS. Convención Americana De Derechos Humanos de 22 de noviembre de 1969. Disponible en: <https://www.oas.org/dil/esp/tratados_americana_sobre_derechos_humanos.htm>. Consulta em 01 de junio de 2017.

\footnotetext{
${ }^{1}$ La Justicia Étnica Como Criterio De Reparación De Víctimas Del Desplazamiento Forzado Y Del Conflicto Armado En Colombia, financiada por la Universidad Tecnológica del Chocó "Diego Luis Córdoba", del cual se desprende el presente artículo.

${ }^{2}$ Roberto Rojas Dávila. Departamento de Derecho Internacional, Secretaría de Asuntos Jurídicos de la OEA, La Evolución de los Estándares Universales de Protección de las y los Afrodescendientes (Presentación). Día Mundial de la Eliminación de la Discriminación Racial (1966), Primer Decenio de la Lucha contra el Racismo y la Discriminación Racial (1973 a 1983), Primera Conferencia Mundial para Combatir el Racismo y la Discriminación Racial (1978), Segundo Decenio de la Lucha contra el Racismo y la Discriminación Racial (1983 - 1992), Segunda Conferencia Mundial para Combatir el Racismo y la Discriminación Racial (1983), Tercer Decenio de la Lucha contra el Racismo y la Discriminación Racial (1993-2003), Tercera Conferencia Mundial contra el Racismo, la Discriminación Racial, la Xenofobia y Formas Conexas de Intolerancia. (2001), Decenio Internacional para los Afrodescendientes (2015-2024), la Asamblea General de la ONU en diciembre de 2014, en su resolución 68/237, proclamó el Decenio Internacional para los Afrodescendientes (2015-2024).

${ }^{3}$ El Estado responsable está obligado a reparar íntegramente el perjuicio causado por el hecho internacionalmente ilícito. 2) El perjuicio comprende todo daño, tanto material como moral, causado por el hecho internacionalmente ilícito del Estado.

${ }^{4}$ Ver Gabriel Rodríguez, Normas de responsabilidad internacional de los Estados.
} 